\title{
'|||||||||||||||||||||||||||||||||||||||||||||||||||||||||||||||||||.
}

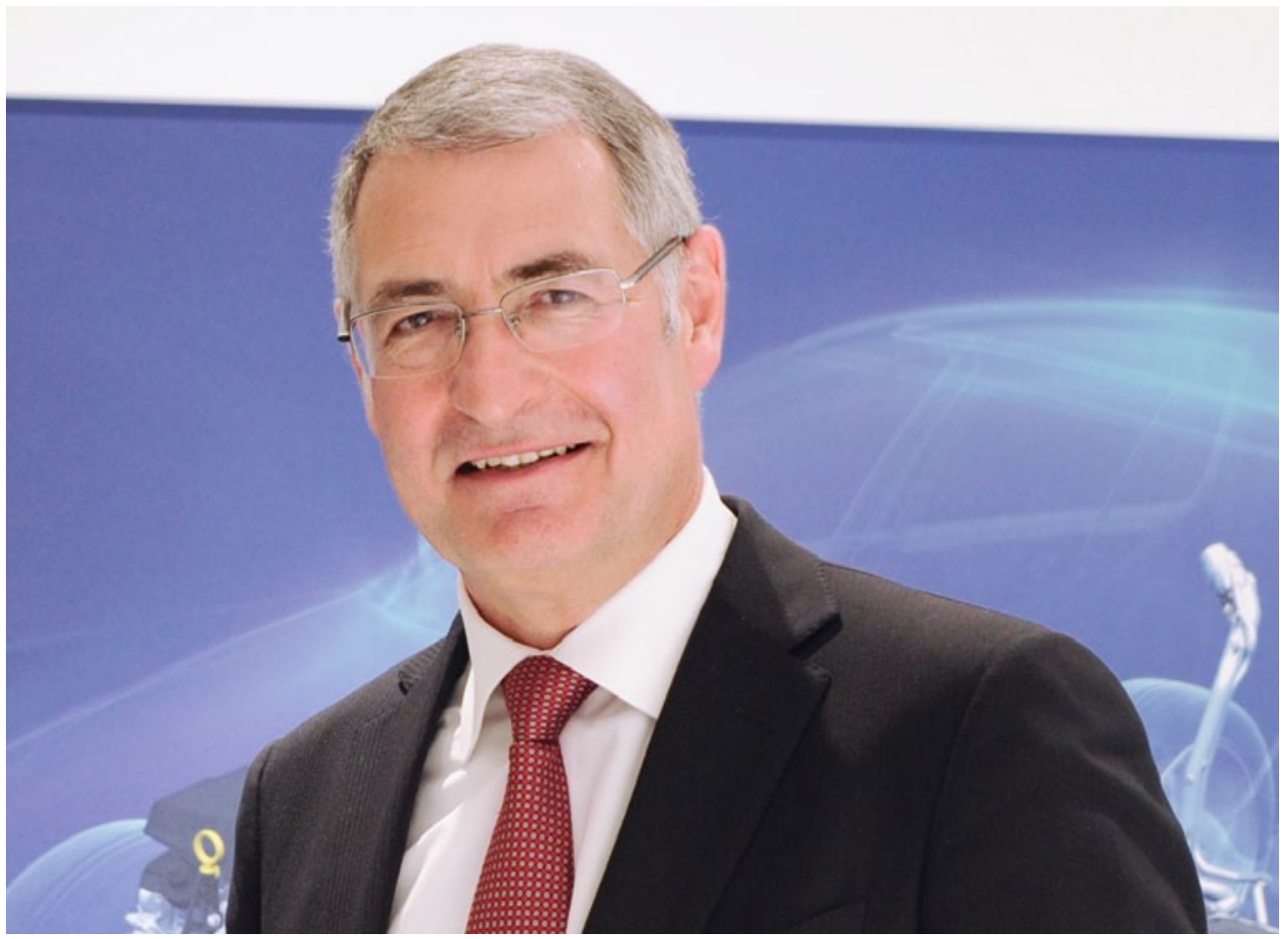

DR. HEINZ-JAKOB NEUSSER

Entwicklungsvorstand der Marke Volkswagen und Leiter Konzern

Aggregateentwicklung

\section{INNOVATIVE ANTRIEBSKONZEPTE}

Der Volkswagen-Konzern hat mit seinen Antriebstechnologien TDI, TSI und DSG in den vergangenen zwei Jahrzehnten Innovationen in Serie gebracht, die den Fortschritt in der Antriebstechnik maßgeblich geprägt haben. Durch Einführung der Direkteinspritzung in Verbindung mit Turboaufladung und variablen Ventiltrieben konnte die spezifische Leistung deutlich gesteigert und dadurch die Hubräume verkleinert beziehungsweise Zylinderzahlen reduziert werden. Das Resultat: Der Kunde „erfährt“ mehr Fahrspaß bei geringerem Kraftstoffverbrauch.

Durch die weltweit anspruchsvollen $\mathrm{CO}_{2}$ - und Abgasemissionsgesetzgebungen liegt bei der Entwicklung von neuen Antrieben ein besonderer Fokus auf der Verringerung des Kraftstoffverbrauchs und der Reduzierung von Abgasemissionen. Die weitere Steigerung der spezifischen Leistung in Verbindung mit gesteigertem Downsizing wird dabei eine zentrale Bedeutung einnehmen. Der konzeptionelle Nachteil der Hubraumreduzierung bezüglich Ansprechverhalten ist durch spezielle Ladungswechselsteuerung, optimierte Brennverfahren sowie verbesserte Aufladetechniken zu kompensieren. Technologien wie variable Ventiltriebssysteme, variable Turbinengeometrien oder elektrisch unterstützte Aufladung können hier zielführende Ansätze sein.

Darüber hinaus werden die Motorenfamilien modular entwickelt, so können mit einem Baukasten verschiedene Motoren mit unterschiedlichen Zylinderzahlen und Leistungen für verschiedene Fahrzeugplattformen und Abgasstandards mit gerin- gem Änderungsumfang abgeleitet werden. Eine Anpassung an alternative Kraftstoffe wie Erdgas und Bioethanol beziehungsweise lokal verfügbare Kraftstoffqualitäten oder auch die Anwendung in einem Hybridantriebsstrang werden dabei ebenfalls berücksichtigt.

Zur Erreichung der zukünftigen $\mathrm{CO}_{2}$-Ziele werden neben den Verbesserungen am klassischen Verbrennungsmotor die weitere Elektrifizierung des Antriebsstrangs und die Reduzierung der Fahrwiderstände erforderlich sein. Mit den erfolgreich im Markt befindlichen Hybridkonzepten konnten bereits wertvolle Erfahrungen für die Betriebsstrategie von elektrifizierten Antrieben gesammelt werden. Im nächsten Schritt folgen die Elektrofahrzeuge e-Up, e-Golf und der Golf TwinDrive, der Plug-in-Hybrid von Volkswagen. Das Elektrofahrzeug eignet sich vor allem für den Kurzstreckenbetrieb. Der Plug-in-Hybrid vereint das Beste aus zwei Welten, emissionsfreies Fahren im innerstädtischen Betrieb und Langstreckenbetrieb mit uneingeschränkter Reichweite. Mit dem XL1 haben wir einen Technologieträger entwickelt, der das derzeit technisch Machbare in Sachen Niedrigverbrauch darstellt.

Anhand der Vielzahl der Technologien lässt sich erkennen, dass dem Antrieb auch zukünftig eine zentrale Bedeutung zukommt. Nur durch innovative modulare Motoren- und Getriebefamilien können die vielseitigen Anforderungen erfüllt werden. Bei Volkswagen freuen wir uns auf diese Herausforderung. 